\title{
Consensus, Polarization, and Alignment in the Economics Profession
}

\author{
Tod S. Van Gunten, ${ }^{a}$ John Levi Martin,, Misha Teplitskiy ${ }^{\mathrm{c}}$
}

a) Max Planck Institute for the Study of Societies; b) University of Chicago; c) Harvard University

Abstract: Scholars interested in the political influence of the economics profession debate whether the discipline is unified by policy consensus or divided among competing schools or factions. We address this question by reanalyzing a unique recent survey of elite economists. We present a theoretical framework based on a formal sociological approach to the structure of belief systems and propose alignment, rather than consensus or polarization, as a model for the structure of belief in the economics profession. Moreover, we argue that social clustering in a heterogeneous network topology is a better model for disciplinary social structure than discrete factionalization. Results show that there is a robust latent ideological dimension related to economists' departmental affiliations and political partisanship. Furthermore, we show that economists closer to one another in informal social networks also share more similar ideologies.

Keywords: profession; polarization; sociology of economics; ideology; networks

Citation: Van Gunten, Tod S., John Levi Martin, and Misha Teplitskiy. 2016. "Consensus, Polarization, and Alignment in the Economics Profession." Sociological Science 3: 1028-1052.

Received: October 8, 2016

Accepted: October 26, 2016

Published: December 5, 2016

Editor(s): Jesper Sørensen, Gabriel Rossman

DOI: $10.15195 / \mathrm{v} 3.245$

Copyright: (C) 2016 The Author(s). This open-access article has been published under a Creative Commons Attribution License, which allows unrestricted use, distribution and reproduction, in any form, as long as the original author and source have been credited. @()

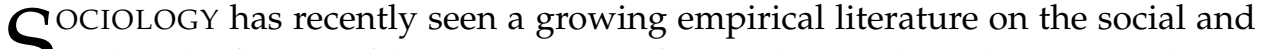
$S$ political influence of the economics profession (Fourcade et al. 2015; Hirschman and Berman 2014; Reay 2012; Van Gunten 2015). Uniquely among the social sciences, contemporary U.S. economics enjoys consensus on a core paradigm based on formal models of individual rationality and collective equilibrium; according to advocates, this approach earns the attention of policy makers by virtue of its ability to formulate "clear, unambiguous policy statements" (Lazear 2000:102). Some sociologists argue that these policy statements have substantial practical impact, particularly as the discipline's increasing emphasis on market efficiency "provided part of the intellectual rationale for the deregulatory movement in public policy and the expanded use of the price and market mechanism" (Fourcade et al. 2015:105) in a variety of policy areas (c.f. Babb 2001; Blyth 2002; Campbell 1998; Chwieroth 2007; Kogut and Macpherson 2007). However, as Reay (2012:46) argues, this literature has produced something of a paradox: although many studies see the profession as a powerful, unified juggernaut, others (including many economists themselves) view the discipline as fragmented and weak. Against the image of economics as a homogeneous advocate of "neoliberal" policies, some economists view their profession as polarized among competing schools or "factions" divided over beliefs about the proper balance of free markets and state intervention (Krugman 2009). Thus, whether paradigmatic consensus is sufficient to generate policy consensus or compatible with ideological division remains an open empirical question.

An observable corollary of this question is whether the "idea space" of mainstream professional economics is constrained (Converse 1964; Martin 2002), such that it is possible to identify an ideological dimension running from advocates of the "free market" to those more amenable to government intervention. In this 
article, we use a survey of elite economists to show that an important subset of economists' policy beliefs do align in this fashion. By "ideology," we refer to the substantive content of these beliefs, which reflects the classic debate between state intervention and free markets. ${ }^{1}$ Our focus on alignment addresses a failure to explicitly define terms such as "polarization" and "faction" in recent debates and, more generally, to place these concepts in the context of a systematic approach to the formal properties of belief systems (Mohr 1998). We argue that factionalism-in the sense of discrete and mutually exclusive group memberships-is a poor model for the economics discipline. Rather, we conceptualize the social structure of the discipline as a heterogeneous topology characterized by informal "communities," or clustering in professional networks. We show that economists with more similar social networks-those that tend to coauthor with the same colleagues-are closer together in ideological space. These findings support an alignment model of the economics profession according to which the field is neither polarized nor fully unified but rather partially structured around the "state versus market" ideological divide.

We support these claims by reanalyzing a recent survey of 51 elite economists in the United States conducted by the Initiative for Global Markets (IGM) at the University of Chicago since 2011. Despite a small, nonrandom sample and other limitations discussed below, the IGM survey has unique features that make it a valuable resource for studying the economics profession. In particular, because responses are public, it is possible to incorporate data on respondents' careers, political activities, and social networks from outside the survey itself. In addition, the IGM survey has already been the object of substantial research (Gordon and Dahl 2013; Sapienza and Zingales 2013) and public discussion (Krugman 2013; Smith 2013), making further analysis valuable insofar as it extends and qualifies previous results. Existing analyses of these data report "no evidence to support a conservative versus liberal divide" among respondents (Gordon and Dahl 2013:635). In contrast, we identify a latent ideological dimension clearly related to contemporary political debates and, more importantly, show that ideological distance between economists is related to partisan and departmental affiliations-as well as to the similarity of respondents' informal social networks.

Our results suggest that paradigmatic consensus does not eliminate ideological heterogeneity in the case of the economics profession. Although there is indeed substantial consensus in the profession, we show that consensus and ideological alignment are not mutually exclusive. However, depictions of the economics discipline as polarized or factionalized overstate the degree of intra-professional conflict; our alignment model provides a better fit to the data and clarifies a debate that itself threatens to become excessively polarized. Thus, our findings qualify both sociological literature that depicts a pro-market consensus and recent arguments that there is no systematic ideological heterogeneity in the economics profession. Moreover, we tentatively interpret our finding of an association between network similarity and ideological proximity as evidence of homophily in coauthorship selection (and possibly self-reinforcing belief formation processes), suggesting that ideology influences not just in hiring processes and political activities but also the research process itself. 


\section{Consensus and Conflict in the Economics Profession}

The notion of economics as a polarized or factionalized field has its roots in deep professional debates during the 1970s. Aided by the economic crisis of stagflation, a professional movement associated with monetarism and the "New Classical" economics succeeded in calling into question the hitherto dominant Keynesian approach (Van Gunten 2015). The labels "freshwater" and "saltwater" (Hall 1976) have come to describe the competing classical, laissez-faire approach associated with the University of Chicago and other Midwestern economics departments, as compared to the more Keynesian economics practiced in coastal universities such as Harvard and MIT. For example, Krugman (2009) describes an economic field "divided into two great factions": "saltwater" economists with a "more or less Keynesian vision of what recessions are all about" and a "freshwater" camp of "neoclassical purists."

On the other hand, many economists argue that the paradigmatic debates of the 1970s have largely been resolved, giving rise to a New Keynesian "consensus" (Blanchard 2009; Blinder 1997). Moreover, the disciplinary feud of the 1970s occurred mainly within the subfield of macroeconomics; microeconomics was arguably less affected. Sociologists and political scientists studying the economics profession and its political influence also observe policy consensus, though they tend to emphasize the "neoclassical" or "neoliberal" orientation of the contemporary field (Babb 2001; Blyth 2002; Chwieroth 2007; Kogut and Macpherson 2007). At the paradigmatic level, relative to other social sciences, economists agree more on standards of research quality and see their field as independent of politics (Lamont 2009; Fourcade et al. 2015); moreover, U.S. economists tend to show greater consensus than those in other countries (Fourcade 2009). Similarly, survey research on the economics profession has generally argued that there is a broad consensus within the mainstream (Alston et al. 1992; Fuller and Geide-Stevenson 2003). ${ }^{2}$

Recent research using the data analyzed in this article mirrors this broader debate. As noted above, one widely discussed paper (Gordon and Dahl 2013) argues that the IGM survey provides strong evidence of professional consensus and the absence of discernible ideology; public discussion has tended to echo this conclusion (e.g., Stevenson and Wolfers 2012). However, some analyses report significant correlations between ideology measures and responses on some politically salient items (Wolfers 2013; Sapienza and Zingales 2013). Similarly, Jelveh et al. (2014) use automated text analysis to detect latent ideology in published economics research and validate their algorithm using these items. However, the claim of Gordon and Dahl (2013) is that the IGM data show aggregate consensus in the belief system of professional economists rather than the (undisputed) point that there is consensus on certain beliefs. Below, we argue that this recent literature has not full recognized the difficulty of quantifying professional consensus; nor have previous studies fully explored latent ideology in the IGM data using appropriate methods.

Debates over whether the economics profession is unified or fragmented suffer from two related theoretical weaknesses. First, these debates lack explicit definitions of terms such as "consensus" and "polarization" and, more generally, grounding in a systematic approach to the formal properties of belief systems. Second, studies have 
explored a relatively limited range of links between professional belief and formal affiliations, such as partisan activities and departmental training or employment (Gordon and Dahl 2013; Sapienza and Zingales 2013). In addition to such affiliation variables, we suggest a focus on informal social structures, such as collaboration networks.

\section{Formal Properties of Belief Systems}

To remedy the first deficiency, we draw on sociological discussions of the formal properties of belief systems (for a review, see Mohr 1998). Much of this work begins with the notion of "constraint" as formulated by Converse (1964). In this tradition, we begin by conceptualizing the structure of belief in the economics profession as a generic "idea space" with as many dimensions as there are measured items. Thus we have N people (in this case "mainstream" economists) distributed in an M-dimensional space. In the absence of any systematic structure or "constraint," we would expect to see the individuals evenly distributed like gas molecules in an M-dimensional box. The deviation of the observed distribution from this extreme may be of two types (Martin 2002). We define "consensus" as gross agreement at the level of the marginals, or a low variance in the distribution along particular beliefs. On the other hand, "tightness" refers to the association of multiple beliefs with one another, even in the presence of disagreement.

An important difficulty in measuring aggregate consensus is that any assessment inevitably depends on the corpus of measured beliefs. Relative claims about consensus are straightforward: we can easily compare the distributions of two or more groups in the same belief space (or a single group over time). Thus, in Figure $1 \mathrm{~A}$, the group denoted by the black circles clearly has higher consensus than that denoted by the open circles (there are the same number of observations in each). But considered by itself, it is impossible to say anything precise about the consensus of a single group other than that it is total or non-total. Short of finding total homogeneity, our measure of consensus will largely be a function of whether or not we have asked about controversial issues. If one measures "core" beliefs that define group membership, one will unsurprisingly find high consensus; conversely, if one measures beliefs that are contested within group boundaries, consensus will appear lower. Below, we suggest that this issue is an important limitation of the IGM data. Hence, in this article, we bracket the question of measuring consensus and instead focus on the observed structure of the variation beyond the marginals.

The alternative to consensus is often expressed as the hypothesis that the field is "polarized" (Gordon and Dahl 2013:630) or "divided into two great factions" (Krugman 2009). These hypotheses require additional elaboration, because polarization is a multidimensional phenomenon (DiMaggio et al. 1996; Baldassari and Gelman 2008; Flache and Macy 2011). The most common conception of polarization is a bimodal distribution with high variance and empty center, as illustrated in Figure 1B. Such a distribution is intuitive, as it collapses quantitative patterns to a qualitative distinction between groups, as implied by a term such as "faction." However, notwithstanding language such as "warring camps," "polarization," and "faction," we suspect that few observers truly believe that the field is divided among 

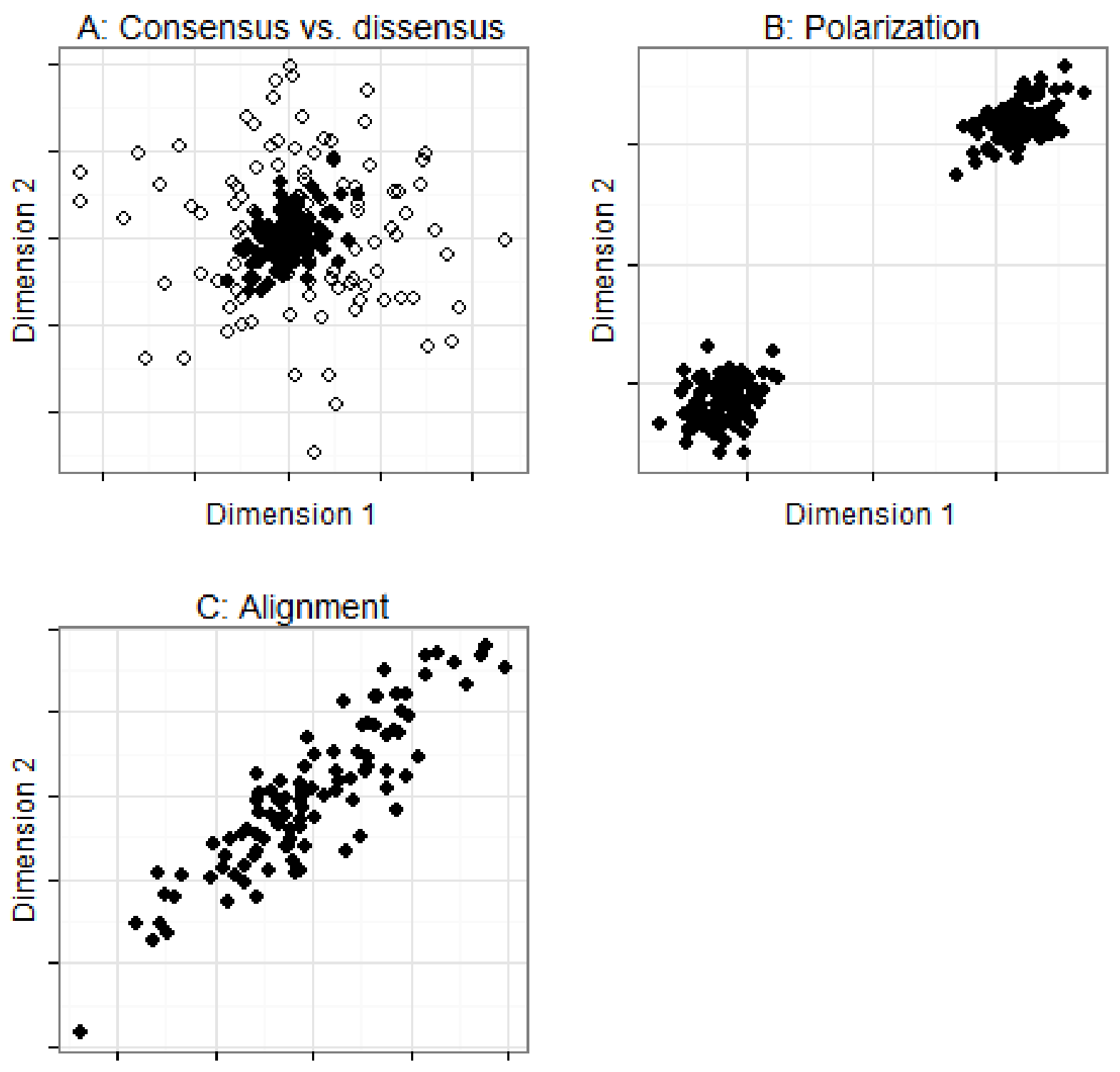

Dimension 1

Figure 1: Hypothetical idea spaces.

fundamentally unreconciled groups with antithetical beliefs. Nor, as we show below, do our data suggest that economics is polarized in this sense. We suggest that "tightness," as defined above, is a better model for the ideological heterogeneity of the economics profession.

To illustrate, note that in Figure 1B, although it is epiphenomenal, there is a high correlation between the two belief dimensions. ${ }^{3}$ It is possible for such a correlation to exist in the absence of polarization, as in Figure 1C. This "tightness" of this idea 
space suggests alignment but not polarization in the sense of a bimodal distribution or missing middle. Such an idea space includes a clear "center" but nevertheless implies that, in the aggregate, certain beliefs tend to be correlated. In contrast to the difficulty of measuring consensus in a single group, it is possible to assess the extent of alignment or tightness without comparative data.

This model also helps illustrate the implications of an important variant of the consensus hypothesis. Recognizing that, in the aggregate, professional consensus is not total, Gordon and Dahl (2013:630) suggest that deviations from the mean in the IGM panel are "idiosyncratic" random individual effects and not evidence of some sort of stable difference of opinion that might indicate ideological heterogeneity In other words, to the extent that consensus falls short of total agreement, heterogeneity in belief is "white noise"; on this view, all constraint in the IGM data takes the form of consensus rather than alignment. We refer to this joint null hypothesisthat professional opinion is a combination of consensus and random variation-as "consensus + noise." Any observation of tightness in a belief distribution falsifies the "noise" proviso of this null hypothesis to the extent that the idea space has more structure than would be expected by chance. We refer to this alternative hypothesis as "consensus + alignment."

Note that in Figure 1A, we may tilt the space so that all the variation is on a single dimension. This sort of successful dimensional reduction is a good way of examining one very common form of tightness-linear associations due to common factors. Given that we do not expect to observe polarization in the bimodal sense (and preliminary analysis did not support the polarization hypothesis), but we do expect alignment, we use such dimensional reduction to explore the logic of the organization of the belief space of economists. In particular, we use principal components analysis (PCA), a widely used and mathematically straightforward form of factor analysis capable of distinguishing either polarization or alignment from noise. By analyzing the substantive content of the survey items that load on the dimension revealed by the analysis, we can retrieve the latent content of this belief structure and interpret its meaning.

\section{From Idea Space to Social Structure}

References to the freshwater/saltwater divide as professional "factionalism" imply that disagreements in economics are rooted in disciplinary social structures. In sociological terms, concepts such as "school," "camp," and "faction" imply relatively stable patterns of interaction, identification, and group formation. For example, the "freshwater/saltwater" distinction implies a field structured at least in part on the basis of academic departments and, thus, on stable organizations, socialization tendencies, and career mobility patterns. Departmental memberships may translate into professional ideologies through socialization (when economists adopt the "worldview" of the program in which they trained) or homophily (if departments tend to hire like-minded colleagues). Consistent with the latter, Terviö (2011) finds that hiring patterns in economics show greater clustering than other disciplines, such as mathematics. To the extent that an economists' position along a formal belief dimension correlates with the distinction between departments typically 
classified "freshwater" or "saltwater," there is further evidence that this dimension reflects latent ideology as we have defined it. Moreover, the substantive content of the free market/intervention in economics mirrors a familiar division between the Republican and Democratic parties in the broader partisan arena. Correlation between party affiliations and position on this dimension is therefore additional evidence in favor of interpreting this dimension as ideological.

Nevertheless, an empirical demonstration that these formal affiliations are associated with position on a belief dimension does not amount to evidence of professional "factionalism." Rather, such a demonstration shows that there are differences, on average, across departmental or partisan lines, but not that these differences coalesce into discrete, mutually exclusive subgroups. Indeed, just as we have argued that polarization is an unlikely model for the idea space of the economics discipline, we also argue that factionalism in this sense is a poor description of the field's social structure. Rather, we propose that the economics field is structured by interaction patterns that result in the emergence of fluid and informal professional communities or "invisible colleges" (Crane 1972), but not discrete factions. Sociologists of science have long observed that networks of scientific interaction are heterogeneous topologies characterized by substantial local clustering (Moody 2004). Two important forms of interaction that can manifest such clustering are coauthorship and citation networks; academics tend to select like-minded colleagues as coauthors and signal affinity through citation (Schwed and Bearman 2010). Recent research in economics supports these observations; Goyal et al. (2006) find that the coauthorship network of economics has "small world" properties consistent with a fragmented field (Moody 2004), and Önder and Terviö (2015) find clustered citation patterns consistent with a freshwater/saltwater divide. From this perspective, economists who share similar social networks are likely to also be closer in the discipline's idea space.

Thus, we model individual economists' latent ideological positions-as inferred from the PCA analysis-as a function of individual affiliations and other background characteristics, in particular whether respondents trained and work in "freshwater" or "saltwater" departments and their affiliations with political parties, if any. Furthermore, we then model the relational ideological distance between pairs of respondents, adding measures of structural equivalence (Wasserman and Faust 1994:347-391) in coauthor networks as predictors to examine whether respondents closer in informal social networks also share more similar ideologies. Though we do not attempt to disentangle the mechanisms that might produce this relationship, our working hypothesis is that an association between network and ideological similarity reflects a combination of homophily in coauthorship selection and self-reinforcing feedback processes.

\section{Data and Methods}

The IGM economic experts panel is a survey of a total of 51 elite, mainstream economists on nearly 200 policy-oriented questions conducted since $2011 .{ }^{4}$ Respondents were selected from among senior faculty in the top seven U.S. economics departments (Berkeley, Chicago, Harvard, MIT, Princeton, Stanford, and Yale). The 
survey designers selected respondents to achieve diversity of geography, age, area of expertise, and partisanship. Clearly, this is not a random sample, which limits the extent to which this survey can be generalized to the economics profession as a whole. For the purpose of demonstrating consensus in the economics profession, this design limitation is a flaw. For example, professional belief may be more heterogeneous outside the top departments, although economists outside this elite are likely no less knowledgeable. Thus, we restrict our conclusions to the mainstream elite of the profession.

Just as the survey is not a random sample of economists, the composition of survey items is problematic from the standpoint of quantifying consensus. Rather than strictly test the hypothesis of professional consensus, the survey seems to have been partially designed to "showcase consensus" (Wolfers 2013). For example, the survey includes many didactic items that illustrate the implications of textbook economics, such as the benefits free trade $(3 / 13 / 12)$, the impossibility of predicting the stock market $(10 / 31 / 2011)$, the disadvantages of the gold standard $(1 / 12 / 12)$ and the state-controlled Cuban economy (5/15/12), and the proposition that vaccine refusal imposes externalities (3/10/2015). Although these items usefully illustrate mainstream professional opinion on particular issues, for the purposes of strictly testing the hypothesis of aggregate consensus, these "softball" items have dubious value, because few observers doubt that there is a consensus on such issues within this mainstream. Had the survey included "heterodox" or "Austrian" economists, it may have encountered a wider range of opinion. Overall, on 30 percent of items, not a single respondent took a position opposite the modal view (i.e., agreed when the modal position was disagree or vice versa). Whether this reflects the strength of professional consensus or a survey biased towards "softball" questions is subjective.

Despite these limitations, the IGM survey is a valuable tool for studying the structure of observed beliefs among elite, mainstream economists. Although the survey includes many uncontroversial items, it also includes numerous items that tap deep recent controversies. For example, the survey includes questions on the financial crises and recession in the United States and Europe, the United Kingdom's exit from the European Union, the minimum wage, and the patent system. In some cases, these items revealed substantial and nontrivial consensus. For example, despite vigorous public debates, the overwhelming majority of respondents agreed that that the Obama fiscal stimulus decreased the unemployment rate. Other items reveal informative debates: for example, a second question on the stimulus package reveals more debate (and more uncertainty) about the more difficult question of whether the benefits of the stimulus exceeded the costs. Thus, the panel reveals substantial variation in professional belief.

As noted above, we use PCA to infer respondents' positions in the latent "idea space." Gordon and Dahl (2013) report failing to identify ideology in these data using cluster analysis; however, this method is unlikely to recover alignment in the sense introduced above. Our approach is to determine whether there is evidence of a constrained (tight) belief structure, and, if so, how many dimensions this space seems to have. We then are interested in whether we can predict individual economists' positions in this space. To the extent that we can, we must reject the 
hypothesis that there is no structuring to the disagreement in the field, that is, that disagreement is simply "noise."

Because PCA requires pairwise-complete observations across a large number of survey items, attrition and nonresponse require careful treatment. The panel initially included 41 participants; due to attrition, the panel was replenished with 10 additional respondents, for a total of 51 panel members. As Figure 2 illustrates, this pattern results in two partially overlapping implicit survey waves; respondents answered only first-wave items, only second-wave items, or both. Replenishment participants also responded retroactively to a small number of items when they joined the panel; these items are thus included in both waves. ${ }^{5}$ Our approach is to use all available data while imposing a threshold for the minimum response rate of 60 percent, ${ }^{6}$ excluding respondents that failed to meet this threshold in either wave, and impute the mean for all remaining missing data. Mean imputation is conservative in that it biases our findings towards finding no factor structure beyond what would be expected under chance, given the distribution on the marginals. Across the two waves, we are able to perform the PCA on 47 respondents. ${ }^{7}$

After presenting the results of the PCA, we use the respondent-level scores inferred by this analysis in two ways. First, we regress individual-level scores on respondent's attributes (collected from their CVs), including their partisan and departmental affiliations, age, gender, place of birth, areas of expertise, and work experience outside academia (i.e., private sector and central banks). We capture "left" and "right" partisan affiliations by combining government appointments under Republican and Democratic administrations and affiliations with partyaligned think tanks. ${ }^{8}$ Following Gordon and Dahl (2013) and Önder and Terviö (2015), we code Harvard, MIT, Princeton, and Berkeley as "saltwater" departments and Chicago, Stanford, and Yale as "freshwater" (comparison group). ${ }^{9}$ Moreover, like Gordon and Dahl (2013), we use respondents' National Bureau of Economic research (NBER) memberships to measure their area of expertise. ${ }^{10}$

Second, we model the absolute difference in individual PCA scores between pairs of respondents as a function of joint characteristics (i.e., common departments, partisan leanings, and shared expertise) and the similarity of respondent's positions in the coauthorship network among respondents. In order to construct the latter, we obtained each respondent's unique coauthors from the publications listed in their $\mathrm{CV}$, cross-referenced shared coauthors, and defined the coauthorship network as all IGM respondents plus all economists who authored a paper with more than one respondent. We measure similarity using the structural equivalence of the respondents' coauthorship networks; our preferred equivalence measure is the Jaccard similarity index, which is the proportion of coauthors of each pair of respondents that are coauthors of both. To control for network size and varying propensities to coauthor with other survey respondents, we include a two measures of network size in our base network model. For reasons discussed in more detail below, we control for both total joint degree (the geometric mean of the number of coauthors in each dyad) and within-panel joint degree (the geometric mean of the number of coauthors who are panel members). ${ }^{11}$ 


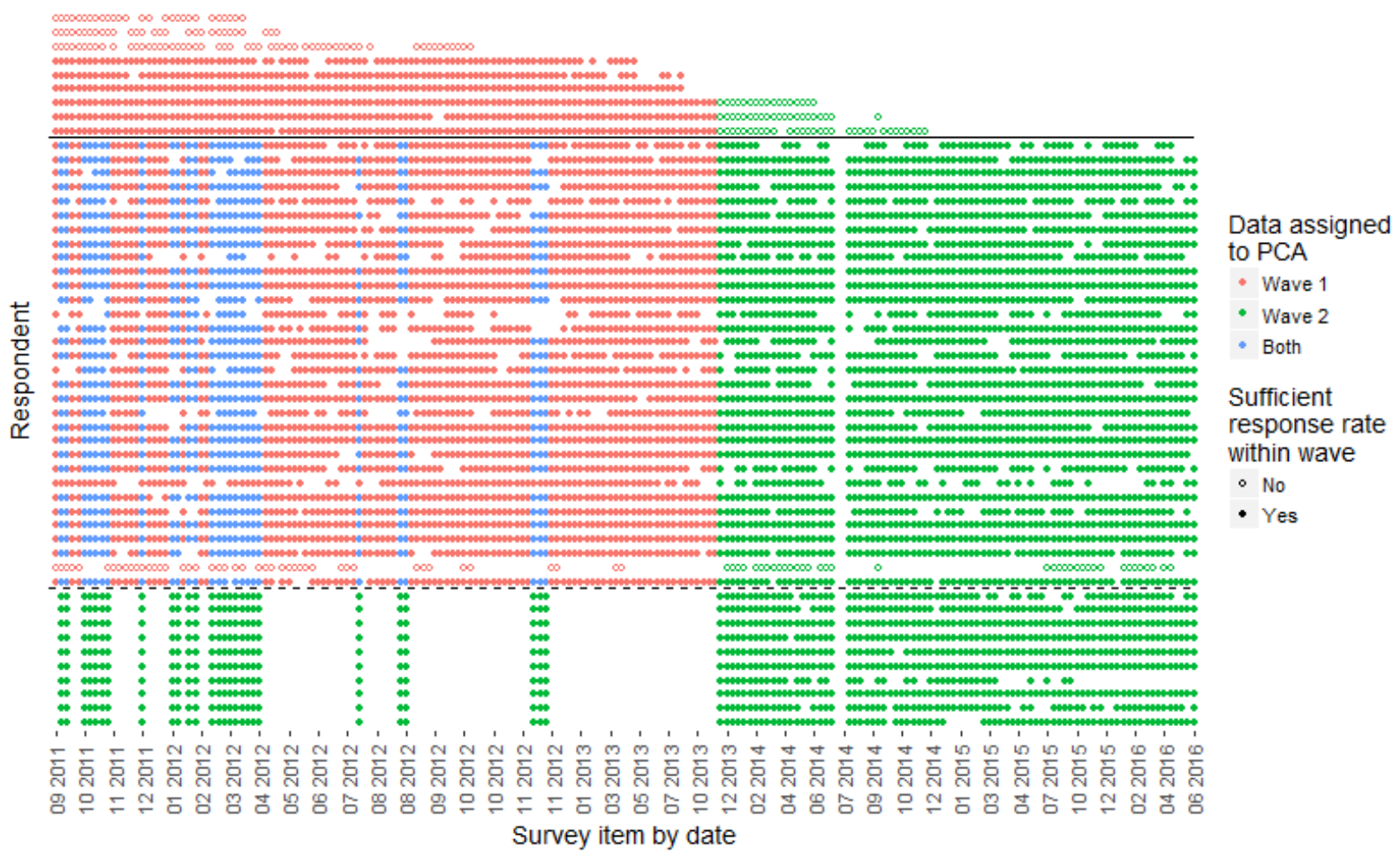

Figure 2: Nonresponse, attrition, and implicit survey waves in the IGM panel. Note: Each point represents a valid response; empty locations indicate nonresponse. Red points represent data analyzed as wave 1. Green points represent data analyzed as wave 2 . Blue points were used in both analyses. These items were retroactively posed to the replenishment respondents when they joined the panel. Hollow points represent valid data that could not be used due to an insufficient response rate within that wave. Respondents positioned between the solid and dotted black lines were included in both waves (i.e., their latent ideology is observed twice), unless the respondent did not maintain a 60 percent response rate. In July-September 2014, the panel "revisited" earlier items; items that replenishment respondents had already answered were excluded.

\section{Results}

PCA reveals one primary dimension in the idea space of professional economists. As Figure 3 shows, this first dimension explains about 10-12 percent of the variance, while the variance explained by additional dimensions declines rapidly. In order to test whether this fraction of variance could be explained by chance, we conducted a permutation test; ${ }^{12}$ in 1,000 iterations, we never once achieved this level of explained variance on the first PCA dimension in either wave. For the 31 respondents active in both waves, we find a correlation of .85 between their individual-level scores across waves, underscoring the robustness of this dimension. However, the crosswave correlation on the second dimension is low (.41), suggesting that PCA fails to recover the same underlying dimension in the two waves. Moreover, although in both waves the second PCA dimension explains a statistically significant fraction of variance (according to our permutation test), the variance explained by the 


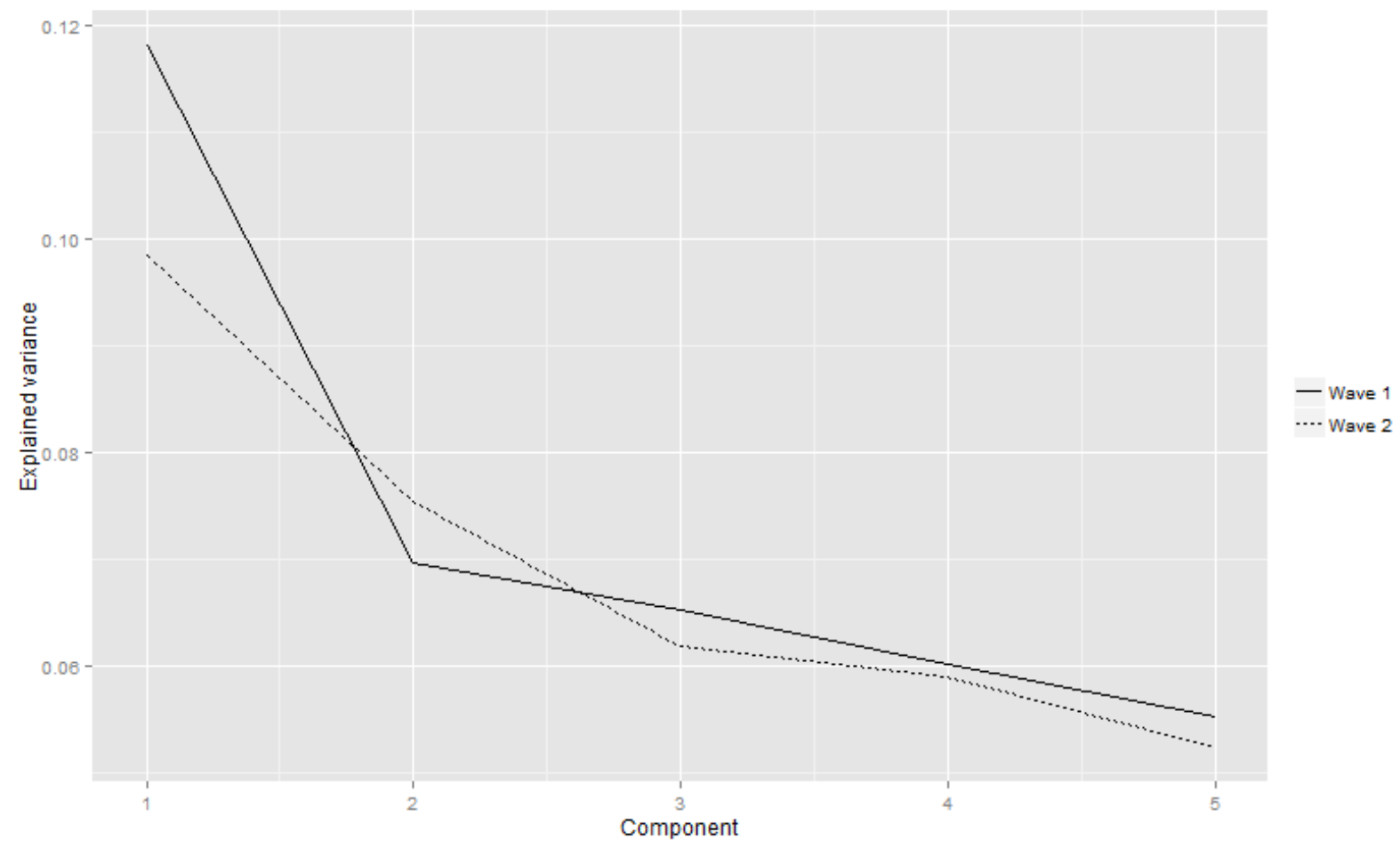

Figure 3: PCA: explained variance.

second dimension falls well within the range explained by chance on the first dimension. This reduces our confidence that the second dimension is interpretable. Thus, we are able to identify only one robust dimension in these data, although we cannot conclusively establish that the idea space of the economics discipline is one-dimensional.

Although the proportion of variance explained is not overwhelming, it represents a clear rejection of the "consensus + noise" null hypothesis (Gordon and Dahl 2013). Moreover, a priori we do not expect all survey items to reflect the same underlying dimension. If (as we show momentarily) the primary dimension revealed by PCA reflects the ideologically freighted issue of state intervention in the marketplace, we do not expect survey items that invoke issues are orthogonal, obliquely related, or particularly nuanced to load on this dimension. For example, questions including whether the patent system benefits software consumers (6/ $24 / 14)$, student loan interest rates (8/8/2013), the efficacy of sanctions on Russia $(3 / 25 / 2014)$, and the effects of taxing soft drinks $(8 / 7 / 2012)$ were posed in ways that do not necessarily tap underlying ideologies. ${ }^{13}$ Furthermore, some questions that might be expected to elicit ideology fail to do so because of question wording. ${ }^{14}$ Given that the survey was not designed to elicit ideology, these and other factors likely add substantial noise.

In order to test whether these results were sensitive to the specification employed, we varied the rules described in the previous section in three ways. First, we raised the response rate threshold from 60 percent to 80 percent (that is, included 
only participants who answered 80 percent or more of items in each wave); we lose data, but the cross-method correlation in scores for the remaining respondents is above .99. Second, we treated "no opinion" responses as missing and imputed rather than combining "no opinion" and "uncertain"; the cross-method correlation is above .98. Finally, we imputed missing data with random values, rather than the mean opinion; correlations ranged between .94 (wave 2) and .99 (wave 1). Therefore, we conclude that our results are not sensitive to the particular coding rules or imputation procedure we employed.

\section{Interpretation of PCA Scores}

We analyze the substantive meaning of the latent dimension revealed by the PCA in two ways. First, Table 1 summarizes the top 10 items that load on this dimension for each wave. ${ }^{15}$ This dimension reflects respondents' beliefs about an array of politically contested issues, such as the Obama administration's responses to the 2008-9 financial crisis and recession, the Affordable Care Act (i.e., "Obamacare"), the minimum wage, inclusion of labor and environmental provisions in trade deals, the division between inflation "hawks" and "doves," and school vouchers. Responses on these familiar political issues line up in the expected directions; for example, support for Obama administration policies during the recession load in a direction opposite of support for school vouchers and skepticism regarding the benefits of infrastructure spending. The dimension touches on microeconomic debates over market failure as well as macroeconomic policy questions. For example, supporters of the Obama policies are more likely to agree that the online retailer amazon.com (which at the time of the survey was involved in a dispute with a publisher over e-book prices) used its market share to affect supply. This implies a correlation between micro- and macroeconomic beliefs, notably tendency to perceive market distortions (even in niche markets) and support for interventionist policies. Similarly, supporters of school vouchers are more likely to believe that laws regulating ticket scalping hurt consumers and to oppose price-gouging regulations during weather emergencies.

These cross-issue correlations imply an ideologically consistent issue dimension running from supporters of recent episodes of state intervention who tend to perceive market failures, to respondents who oppose policy interventions and are suspicious of market failure arguments. By ideology, we simply mean that the substantive meaning of this latent dimension corresponds to a familiar set of debates over the proper role of government and the ability of unregulated markets to achieve efficiency and equity. We do not equate the terms "ideological" and "normative"; ideological positions in general can be understood as ontological beliefs about the nature of reality rather than values (Martin and Desmond 2010). For example, the belief that "government intervention is generally inefficient" both has ideological content and reflects ontological beliefs that can be grounded in evidence and research. Our argument is about the alignment of beliefs that relates to the proper role of government intervention and markets and not to the underlying origin of these beliefs. 
Table 1: IGM panel items related to latent ideology.

\begin{tabular}{|c|c|c|}
\hline Date & Topic & Belief implied by "agree" response \\
\hline \multicolumn{3}{|l|}{ Wave 1} \\
\hline $2 / 26 / 2013$ & Minimum Wage & Raising minimum wage is desirable. (-) \\
\hline $11 / 13 / 2012$ & Bailouts: Banks and Automakers & 2009 automaker bailouts were beneficial.(-) \\
\hline $10 / 17 / 2011$ & Education & School vouchers improve educational quality. $(+)$ \\
\hline $5 / 23 / 2013$ & Infrastructure & Public infrastructure spending has low returns. (+) \\
\hline $2 / 15 / 2012$ & Economic Stimulus & 2009 fiscal stimulus was beneficial. (-) \\
\hline $7 / 3 / 2012$ & Europe & $\begin{array}{l}\text { Germany should not demand labor reforms and aus- } \\
\text { terity in exchange for bailouts of Southern Europe.(-) }\end{array}$ \\
\hline $3 / 27 / 2013$ & Trade Deals & $\begin{array}{l}\text { Trade deals should not include labor and environ- } \\
\text { mental rules. }(+)\end{array}$ \\
\hline $11 / 13 / 2012$ & Bailouts: Banks and Automakers & 2008 Bank bailouts were beneficial.(-) \\
\hline $4 / 16 / 2012$ & Ticket Resale & Ticket scalping laws hurt consumers. $(+)$ \\
\hline $5 / 2 / 2012$ & Price Gouging & $\begin{array}{l}\text { Government should prevent price gouging during } \\
\text { weather emergencies.(-) }\end{array}$ \\
\hline \multicolumn{3}{|l|}{ Wave 2} \\
\hline $4 / 7 / 2015$ & Raising Interest Rates & $\begin{array}{l}\text { Federal Reserve should not preemptively raise inter- } \\
\text { est rates.(-) }\end{array}$ \\
\hline $12 / 8 / 2015$ & U.S. Interest Rates & $\begin{array}{l}\text { Federal Reserve should have raised interest rates } \\
\text { earlier. }(+)\end{array}$ \\
\hline $11 / 20 / 2015$ & Quarterly Earnings & $\begin{array}{l}\text { Annual (rather than quarterly) earnings reports } \\
\text { would allow executives to concentrate on the longer- } \\
\text { run.(-) }\end{array}$ \\
\hline $11 / 20 / 2015$ & Quarterly Earnings & $\begin{array}{l}\text { Annual (rather than quarterly) earnings reports } \\
\text { would benefit shareholders(-). }\end{array}$ \\
\hline $2 / 15 / 2012$ & Economic Stimulus & 2009 fiscal stimulus was beneficial.(-) \\
\hline $10 / 5 / 2015$ & Health Insurance Subsidies & Benefits of Affordable Care Act will exceed costs.(-) \\
\hline $9 / 22 / 2015$ & \$15 Minimum Wage & $\begin{array}{l}\text { Raising minimum wage to } \$ 15 / \text { hour will increase } \\
\text { unemployment. }(+)\end{array}$ \\
\hline $9 / 22 / 2015$ & \$15 Minimum Wage & $\begin{array}{l}\text { Raising minimum wage to } \$ 15 / \text { hour will increase } \\
\text { GDP.(-) }\end{array}$ \\
\hline $11 / 13 / 2012$ & Bailouts: Banks and Automakers & 2009 automaker bailouts were beneficial.(-) \\
\hline $10 / 28 / 2014$ & Amazon and Market Power & $\begin{array}{l}\text { Amazon.com uses market power to reduce book } \\
\text { supply.(-) }\end{array}$ \\
\hline
\end{tabular}

Notes: Sign indicates direction of the item's influence on PCA dimension 1; positive weights imply more pro-market positions. Beliefs are summaries of survey items; full item wording can be found at http://www.igmchicago.org/igm-economic-experts-panel using the question topics and dates reported in the table. Questions on automaker bailouts and economic stimulus appear in both survey waves because respondents joining the panel in the second wave were asked these questions retroactively. 
Table 2: Linear models of respondents' latent ideology.

\begin{tabular}{|c|c|c|c|c|c|c|}
\hline & \multicolumn{6}{|c|}{ PCA dimension 1} \\
\hline & (1) & (2) & (3) & (4) & (5) & (6) \\
\hline Right & $\begin{array}{r}2.339^{+} \\
(0.895)\end{array}$ & $\begin{array}{r}2.141^{*} \\
(0.762)\end{array}$ & $\begin{array}{r}2.131^{\dagger} \\
(0.894)\end{array}$ & & $\begin{array}{c}2.097^{*} \\
(0.770)\end{array}$ & $\begin{array}{r}2.290^{\dagger} \\
(0.903)\end{array}$ \\
\hline Left & $\begin{array}{c}-1.110 \\
(0.734)\end{array}$ & $\begin{array}{c}-0.863 \\
(0.627)\end{array}$ & $\begin{array}{c}-1.381 \\
(0.747)\end{array}$ & & $\begin{array}{r}-1.727^{+} \\
(0.696)\end{array}$ & $\begin{array}{r}-1.154 \\
(0.870)\end{array}$ \\
\hline Saltwater dept. faculty & & $\begin{array}{r}-1.975^{*} \\
(0.467)\end{array}$ & & & $\begin{array}{r}-1.649^{*} \\
(0.481)\end{array}$ & $\begin{array}{r}-1.607^{*} \\
(0.514)\end{array}$ \\
\hline Saltwater dept. graduate & & & $\begin{array}{c}0.859 \\
(0.581)\end{array}$ & & & \\
\hline Female & & & & $\begin{array}{c}0.083 \\
(0.783)\end{array}$ & $\begin{array}{c}-0.634 \\
(0.609)\end{array}$ & $\begin{array}{r}-0.116 \\
(0.702)\end{array}$ \\
\hline Foreign born & & & & $\begin{array}{c}-0.935 \\
(0.660)\end{array}$ & $\begin{array}{c}-0.856 \\
(0.562)\end{array}$ & $\begin{array}{r}-0.994 \\
(0.682)\end{array}$ \\
\hline Professional age & & & & $\begin{array}{c}-0.020 \\
(0.030)\end{array}$ & $\begin{array}{c}-0.026 \\
(0.023)\end{array}$ & $\begin{array}{c}-0.031 \\
(0.025)\end{array}$ \\
\hline Private sector exp. & & & & $\begin{array}{c}0.660 \\
(0.673)\end{array}$ & $\begin{array}{r}1.087^{\dagger} \\
(0.522)\end{array}$ & $\begin{array}{c}0.836 \\
(0.717)\end{array}$ \\
\hline Central bank exp. & & & & $\begin{array}{c}1.223 \\
(0.743)\end{array}$ & $\begin{array}{c}0.861 \\
(0.589)\end{array}$ & $\begin{array}{c}0.494 \\
(0.685)\end{array}$ \\
\hline Macro & & & & & & $\begin{array}{c}0.779 \\
(0.639)\end{array}$ \\
\hline International & & & & & & $\begin{array}{c}-0.891 \\
(1.028)\end{array}$ \\
\hline Finance & & & & & & $\begin{array}{c}0.493 \\
(0.861)\end{array}$ \\
\hline Labor & & & & & & $\begin{array}{c}-0.331 \\
(0.668)\end{array}$ \\
\hline Public Finance & & & & & & $\begin{array}{c}-0.433 \\
(0.640)\end{array}$ \\
\hline Industrial organization & & & & & & $\begin{array}{c}0.172 \\
(0.726)\end{array}$ \\
\hline Constant & $\begin{array}{c}-0.059 \\
(0.320)\end{array}$ & $\begin{array}{r}0.928^{+} \\
(0.359)\end{array}$ & $\begin{array}{c}-0.539 \\
(0.453)\end{array}$ & $\begin{array}{c}0.364 \\
(1.014)\end{array}$ & $\begin{array}{c}1.509 \\
(0.808)\end{array}$ & $\begin{array}{c}1.539 \\
(1.106)\end{array}$ \\
\hline $\mathrm{R}^{2}$ & 0.194 & 0.431 & 0.233 & 0.116 & 0.536 & 0.579 \\
\hline Adjusted $R^{2}$ & 0.158 & 0.391 & 0.180 & 0.009 & 0.438 & 0.394 \\
\hline
\end{tabular}

Notes: OLS estimates; $\mathrm{n}=47 ;+p<0.01 ;{ }^{*} p<0.05$

In order to further confirm this interpretation, we pool individual's position on the first principal component across the two waves ${ }^{16}$ and regress them on respondent's attributes, including political affiliations and the academic departments in which they were educated and are employed. Results are reported in Table 2. First, 
a dummy reflecting conservative political affiliations is statistically significant; the corresponding dummy for left-leaning affiliations is not significant, though its sign is in the expected direction. ${ }^{17}$ Second, faculty employed in "saltwater" departments lean to the left of faculty at "freshwater" departments (comparison group). As expected, "saltwater" employment and "left" have the same sign. In contrast, we find no evidence that graduates of "saltwater" departments have different views from those of other departments: the coefficient for this term is not significant, and its sign is in the opposite of the expected direction. ${ }^{18}$ Thus, there is evidence of ideological homophily in departmental recruitment and hiring, but not that economists are socialized through their training to adhere to the ideology that prevails in their department.

These findings are summarized in Figure 4, which depicts position on the first PCA dimension on the horizontal axis. Departmental and partisan affiliations account remarkably well for the first PCA dimension: with only two exceptions, respondents more than half a standard deviation above the mean are either faculty at a "freshwater" department, affiliated with a right-leaning organization, or both, while respondents more than half a standard deviation below the mean are either faculty at a saltwater department, affiliated with a left-leaning organization, or both. Two departmental outliers (a saltwater conservative and freshwater liberal) are accounted for by the their partisan affiliations, leaving only two liberal respondents in a freshwater department. Respondents with left-wing affiliations are more evenly split between the center and the left (and hence cannot be statistically distinguished from the center), though none fall on the right. There is a sizable middle that includes faculty at both fresh and saltwater departments, as well as half of respondents with left-wing affiliations (though only one right-affiliated respondent of five falls in the center). Thus, the field is not polarized, but aligned.

Models 4 through 6 check the robustness of these results by adding control variables. We expect female (May et al. 2014) and foreign-born (Fourcade 2009) economists to be somewhat more interventionist, whereas older economists and those with private sector and central banking experience may be more pro-market. With the exception of female, coefficients are in the expected direction, though none are significant at the .05 level. However, as model 5 shows, controlling for these factors does not substantively change the coefficients for departmental and partisan affiliations (if anything, controlling for this set of variables, the left group is statistically distinguishable from the center). Adding a series of dummies for area of expertise does not alter the basic finding. Respondents with private sector experience (such as corporate board memberships and consulting) may hold more conservative views, but this variable is not consistently significant.

Especially given a small sample size, these findings amount to a strong rejection of the "consensus + noise" null hypothesis. Faculty at "freshwater" departments take positions that are more pro-market than their saltwater colleagues; moreover, economists with right-wing partisan affiliations are measurably to the right of their colleagues with no affiliation and those with left-wing affiliations. As Figure 4 shows, these patterns are remarkably consistent. Thus, contrary to the claim that there is "no evidence to support a conservative versus liberal divide" (Gordon and Dahl 2013) or across departments in the IGM panel, we find clear evidence of ideo- 


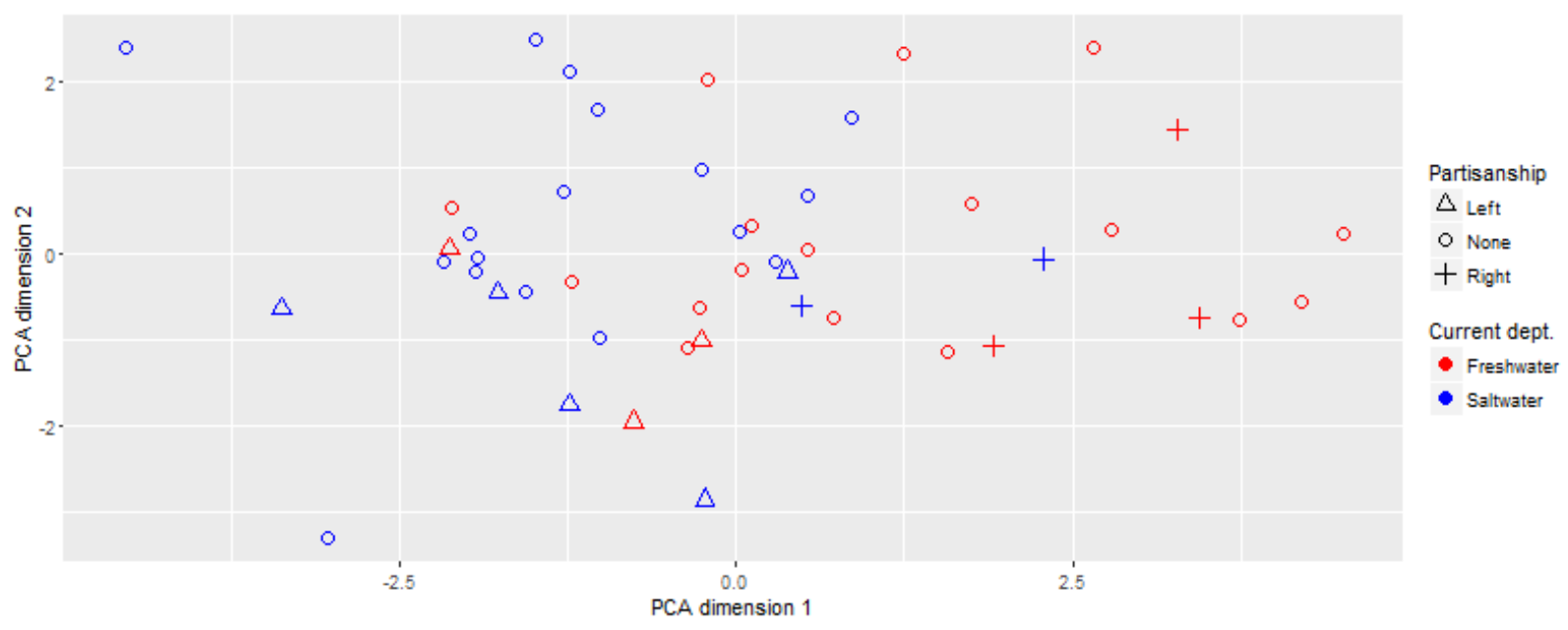

Figure 4: PCA results. Note: Each axis is scaled to the variance explained by the corresponding PCA dimension. Position on vertical axis is provided for visual clarity; this axis has no substantive interpretation (see text).

logical alignment on a dimension that runs from pro-market to pro-interventionist positions.

\section{Dyadic Analysis}

Above, we argued that focusing on formal affiliation variables such as party and department ignores important informal disciplinary social structures. In particular, we proposed that coauthorship networks provide a means of measuring the heterogeneous topology of "invisible colleges," or clusters of like-minded scholars. In this section, we test whether respondents with similar social networks also share similar ideologies. Results are reported in Table 3.

In order to model the relationship between network similarity and ideological distance, we begin with a baseline specification that includes two measures of network size as well as our main network variable, the Jaccard similarity index. Because higher-order network measures are frequently sensitive to network size, it is often necessary to include separate covariates to net out these lower-order effects. In this case, although the denominator of the Jaccard index standardizes the joint size of a dyad's network by dividing by the total number of coauthors of each pair, this does not eliminate the correlation between this index and our measure of joint network size. Moreover, this standardization does not account for an important feature of our data: namely, the fact that some respondents coauthor with other 
Table 3: Linear model of dyadic difference in latent ideology.

\begin{tabular}{|c|c|c|c|c|}
\hline & \multicolumn{4}{|c|}{ Absolute distance on PCA dimension 1} \\
\hline & (1) & (2) & (3) & (4) \\
\hline Network equivalence & $\begin{array}{c}-2.870 \\
(0.033)^{*}\end{array}$ & $\begin{array}{c}-4.663 \\
(0.001)^{\dagger}\end{array}$ & $\begin{array}{c}-4.441 \\
(0.001)^{\dagger}\end{array}$ & $\begin{array}{c}-3.974 \\
(0.009)^{\dagger}\end{array}$ \\
\hline Joint network size & $\begin{array}{c}-0.051 \\
(0.180)\end{array}$ & $\begin{array}{c}-0.055 \\
(0.147)\end{array}$ & $\begin{array}{c}-0.055 \\
(0.138)\end{array}$ & $\begin{array}{c}-0.041 \\
(0.279)\end{array}$ \\
\hline Joint panel coauthors & $\begin{array}{c}0.374 \\
(0.029)^{*}\end{array}$ & $\begin{array}{c}0.346 \\
(0.029)^{*}\end{array}$ & $\begin{array}{c}0.346 \\
(0.039)^{*}\end{array}$ & $\begin{array}{c}0.341 \\
(0.043)^{*}\end{array}$ \\
\hline Expertise overlap & & $\begin{array}{c}0.415 \\
(0.006)^{\dagger}\end{array}$ & $\begin{array}{c}0.400 \\
(0.010)^{\dagger}\end{array}$ & $\begin{array}{c}0.374 \\
(0.012)^{*}\end{array}$ \\
\hline Both party-neutral & & & $\begin{array}{c}0.005 \\
(0.982)\end{array}$ & $\begin{array}{c}-0.018 \\
(0.942)\end{array}$ \\
\hline Both right & & & $\begin{array}{c}-1.076 \\
(0.150)\end{array}$ & $\begin{array}{c}-1.143 \\
(0.106)\end{array}$ \\
\hline Both left & & & $\begin{array}{c}-0.725 \\
(0.151)\end{array}$ & $\begin{array}{c}-0.663 \\
(0.181)\end{array}$ \\
\hline Different party & & & $\begin{array}{c}1.065 \\
(0.004)^{\dagger}\end{array}$ & $\begin{array}{l}1.053 \\
(0.006)^{\dagger}\end{array}$ \\
\hline Salt-fresh & & & & $\begin{array}{l}0.666 \\
(0.015)^{*}\end{array}$ \\
\hline Intercept & $\begin{array}{c}2.567 \\
(0.000)^{\dagger}\end{array}$ & $\begin{array}{c}2.531 \\
(0.000)^{\dagger}\end{array}$ & $\begin{array}{c}2.521 \\
(0.000)^{\dagger}\end{array}$ & $\begin{array}{c}1.861 \\
(0.001)^{\dagger}\end{array}$ \\
\hline $\mathrm{R}^{2}$ & 0.037 & 0.061 & 0.083 & 0.107 \\
\hline Adjusted $\mathrm{R}^{2}$ & 0.035 & 0.057 & 0.076 & 0.100 \\
\hline
\end{tabular}

Notes: Two-sided quadratic assignment procedure $p$-values in parentheses; $\mathrm{n}=1,081 ;+p<0.01 ;{ }^{*} p<0.05$.

members of the IGM panel, while others do not. Examination of the correlation matrix among these variables shows that although both size measures (total joint degree and joint within-survey coauthors) are positively correlated with the Jaccard index, they have opposite correlations with ideological distance. Because of this pattern of correlations, it is necessary to control both size variables in order to isolate the relationship between network similarity and ideological distance.

Model 1 shows this pattern: network similarity is significantly and negatively associated with ideological distance, ${ }^{19}$ whereas the dyadic mean number of coauthorsthat is, the extent to which a pair tends to coauthor with other respondents-is significantly and positively related to distance. Although our interpretation of this latter effect is tentative, it suggests that the choice of panel members as coauthors differs systematically from their non-panel coauthors, possibly reflecting the fact that panelists were selected on the basis of their high status and visibility in the profession, whereas their coauthors (on average) are likely to be lower status and less well-known. In particular, high-status opinion leaders within the profession may have clearer ideological positions than their less visible colleagues. Were this 
the case, the decision to collaborate with other panelists carries greater information about any focal economist's own ideological position, which would explain the positive association we observe.

However, our main interest is in the negative relationship between network similarity and ideological distance. This coefficient implies that respondents with more similar social networks are also more ideologically similar. Results are similar using an alternative (correlation-based) measure of structural equivalence and a proximity-based model that includes indicators for direct and indirect ties. ${ }^{20} \mathrm{In}$ order to check for possible omitted variables, we first introduce a measure of shared expertise. Although none of the controls for expertise were significant in the OLS models above, because economists are more likely to coauthor if they share interests, it is possible that the association between network similarity and ideological distance reflects shared expertise rather than the effects of social networks per se. To account for this, we add an indicator for the number of shared areas of expertise (as measured by NBER memberships) in model 2. Not only is the network effect robust to this control, it increases substantially. At the same time-surprisinglyrespondents with more similar interests are actually further apart in ideological space than those with no overlapping interests. We interpret this unexpected positive association as a design effect due to the composition of the IGM panel. The survey designers chose respondents to achieve variation on substantive expertise as well as political leanings. The positive relationship between expertise overlap and ideological distance suggests that panel selection followed a tacit "Noah's ark" approach, in which designers selected respondents of the same "species" on opposite sides of the ideological divide.

Models 3 and 4 add joint political and departmental affiliations to the dyadic model in order to test whether network similarity is a reflection of the effects reported above. Controls are consistent with the results reported in Table 2 above, but network similarity continues to have a strong negative association with ideological distance after controlling for these variables. Similarly, a control for dyads split across freshwater and saltwater departments is significant but does not alter the substantive import of network similarity. Thus, this relationship is robust to the party and departmental effects observed in Table 2 .

Thus, the more similar the informal social networks of economists, the more similar the latent ideology of their policy views. We are not suggesting that informal disciplinary structures are an exogenous cause of ideological positions. It is equally likely that the opposite is the case: economists choose their coauthors on the basis of their compatibility on several dimensions, including ideology. Thus, two of our main findings are probably explained at least in part by social homophily: ideologically like-minded economists tend to hire one another as colleagues and choose the same coauthors. However, more complex feedback processes may also be involved: for example, a right-leaning department is more likely to hire a right-leaning colleague, but frequent interaction post-hire also reinforces existing dispositions, accentuating differences across departments, parties, and coauthor clusters. Our goal in this article is not to sort through such complex processes but rather to demonstrate that ideological heterogeneity is both real and consistently related to informal social structure as well as formal affiliation. 


\section{Conclusions}

Prior published research on the IGM panel has emphasized consensus in the economics profession; this conclusion has had ample repercussion in public debate. We bracket the question of measuring consensus-which we argue is difficult to address without comparative data and is highly contingent on the survey instrument employed-and focus instead on issue alignment. Our findings falsify the null hypothesis of "consensus + noise" in favor of the alignment model. Although there is undoubtedly consensus on many issues in the economics profession, this does not imply that the remaining variation is purely "idiosyncratic" white noise, or that professional opinion is devoid of ideology. Rather, using more data and methods better suited to this question, we identify a consistent ideological dimension in economists' beliefs; this ideological dimension touches on some of the most pressing public policy issues addressed by the survey. In short, professional opinion is more constrained - in the sense of alignment of opinion across beliefs-than the "consensus + noise" null hypothesis implies; furthermore, this organization of belief is clearly related to partisanship, to department, and to the informal social structure of the discipline.

Some observers may find the fact that economists are ideologically heterogeneous unsurprising. However, recent literature has argued otherwise, and we know of no other study to identify latent ideology in the economics profession using survey data. More fundamentally, it is important to underscore that we identify this heterogeneity within the narrow mainstream elite represented by faculty at the top seven departments. Many critics of mainstream economics assume that the free market/interventionist divide within economics is mainly a contrast between an "orthodox" mainstream and heterodox dissenters from the "neoclassical" consensus. Our findings show that the state/market rift exists within the mainstream, not just between the mainstream and periphery of the discipline. Critics might argue that the mainstream "interventionists" identified by our analysis are still fundamentally "free market" (relative to their own point of reference). ${ }^{21}$ We suggest that empirical analysis of the economics discipline is more fruitfully guided by understanding this as an instance of the fractal character of disciplinary social structure (Abbott 2001) and the constitutive misunderstandings that this entails (for a discussion, see Van Gunten 2015).

Some analysis of consensus in the economics discipline appears motivated, if tacitly, by the assumption that where professionals hold a broad consensus, this consensus should inform public policy. Although the recent academic literature on professional consensus is circumspect, popular discussions of the IGM survey in particular make this point explicit (Stevenson and Wolfers 2012). One implication of our findings is that consumers of economic expertise must exercise healthy skepticism faced with the claim that professional opinion is free of political ideology. Conversely, however, we also emphasize that language of professional "polarization" and "factions" is overblown. Professional belief is aligned on a subset of ideologically freighted items, but not polarized: one implication of this is that there is a substantial center. 
Finally, our finding that ideological proximity is associated with informal network similarity shows that ideology is not just a correlate of formal organizational structures but also plays some role in economists' research activities. Our tentative working hypothesis is that the association between network similarity and ideological proximity reflects homophily in coauthor selection (and possibly self-reinforcing processes). If true, this implies that economists choose ideologically similar coauthors as research partners, which may limit the range of hypotheses, interpretations, and implications they consider. In this sense, our results support the finding of Jelveh et al. (2014) that latent ideology is present in published research. Again, our goal is not to denounce economics as an inherently ideologically driven enterprise but rather encourage healthy skepticism in the consumption of economic expertise.

\section{Notes}

1 We do not mean to suggest that holding beliefs on this dimension means that the research produced by economists is necessarily biased, only that their policy beliefs reflect dispositions substantively related to political debates.

2 Polarization or consensus within the professional mainstream is distinct from divisions between this mainstream and the professional periphery or "heterodoxy." See Dequech (2007) for a discussion of the distinction between "mainstream," "orthodox," and "heterodox" economics. Although drawing boundaries around the "mainstream" is empirically challenging, in this article, we study the less ambiguous mainstream elite.

3 We call this epiphenomenal because, conditional on one's placement in one of the two great groups, the items are independent.

4 The survey remains active at the time of writing; our analysis is based on data collected through May 2016. Data are available at www.igmchicago.org/igm-economic-expertspanel.

5 This introduces a limited amount of redundancy because some responses are used twice but enables us to use all the available data. However, we exclude items that were "revisited" by the panel and answered by the replenishment respondents (i.e., the same question was asked twice), because these items are redundant.

6 We also include two respondents whose response rate was 59 percent. The average individual response rate is 75 percent.

7 Our analysis codes "(dis)agree" and "strongly (dis)agree" as (negative) 1 and 1.5 and collapses "uncertain" and "no opinion" into a single neutral response coded zero.

8 We pool partisan and think tank affiliations in order to maximize the available information about respondents' political memberships. Whereas ten respondents held positions in a Democratic administration, only two respondents held positions under Republican administrations (one of whom we must drop due to nonresponse). However, one respondent is affiliated with the conservative American Enterprise Institute, and four are senior fellows at the Hoover Institution. Although Hoover is officially nonpartisan, surveys of congressional staff and journalists class the institution as conservative (Rich 2005). We only include senior fellows, because short-term visiting fellowships may not reflect ideological alignment with the organization's mission. See below for additional validation of this assumption. 
9 Although Yale and Princeton are not always identified as clearly fresh or salty, Önder and Terviö (2015) rank Yale as fresher than Chicago, whereas Princeton is the second saltiest department.

10 We impute substantive expertise to the few respondents that are not NBER members based on their publications and stated specialization. Unlike Gordon and Dahl, however, we account for the fact that economists have more than one area of expertise by coding the dummy for each broad interest area as one if the respondent is a member of any of the corresponding NBER programs.

11 In other words, these measures are defined as $\sqrt{d_{i} \times d_{j}}$, where $\mathrm{d}=$ the degree measure in question.

12 Specifically, each iteration of this test randomly permutes the observed responses on each item across respondents and then runs the PCA on the randomized data. We then compute the number of iterations (out of 1,000) in which we achieved a level of explained variance greater or equal to the observed data.

13 For example, although beliefs regarding taxation of soft drinks might be ideologically inflected, this survey item asked whether such taxes were likely to result in substitution for other forms of calories. Ideological opposition to taxes on sugar might not depend on this belief about consumer behavior.

14 For example, the survey's first item (9/29/11) asked whether Federal Reserve policies would increase GDP growth "by at least one percentage point" - an extremely large effect for monetary policy. In comments, several respondents indicated that they expected an effect, but not on the order of 1 percent.

15 Two items appear twice because they were among the items posed retroactively to the replenishment respondents.

16 Because respondents' first dimension scores from the two waves are highly correlated, we combine them by standardizing scores and using either the score from their one active wave or (when possible) an average of the two.

17 We also find that, in a model that includes separate dummies for each of the three types of conservative affiliation (Republican administration, American Enterprise Institute, and Hoover) as well as for affiliations with Democratic administrations, the Hoover dummy is statistically significant, and all coefficients have their expected signs. Thus, there is strong support for classing Hoover as a conservative affiliation and pooling these terms.

18 Because respondents graduated from a wider range of departments than those in which they are employed, we explored a variety of alternative specifications, all of which yielded similar results.

19 To be clear, the implication of the preceding paragraph is that a two-tailed test of this relationship is not statistically significant in the absence of the control for within-survey coauthors, though a one-tailed test is significant at the 0.05 level, with the expected sign, in the simple bivariate model.

20 Network theorists distinguish between structural equivalence and cohesion (i.e., proximity) measures; however, when indirect ties are taken into account, these measures are usually highly correlated (Mizruchi 1993), as they are in these data. Thus, we do not attempt to distinguish between equivalence and proximity, as our argument is applicable to both.

21 Conversely, Austrian (i.e., libertarian) economists have tried to show that mainstream economics is not "free market" by conducting surveys heavily skewed towards "litmus 
test" questions around support for regulation in markets for drugs, gambling, and prostitution (Klein and Stern 2007).

\section{References}

Abbott, Andrew. 2001. Chaos of Disciplines. Chicago: University of Chicago Press.

Alston, Richard M., J. R. Kearl, and Michael B. Vaughan. 1992. "Is there a Consensus Among Economists in the 1990s?" American Economic Review 82:203-209.

Babb, Sarah. 2001. Managing Mexico: Economists from Nationalism to Neoliberalism. Princeton: Princeton University Press.

Baldassari, Delia, and Andrew Gelman. 2008. "Partisans without Constraint: Political Polarization and Trends in American Public Opinion." American Journal of Sociology 114:408-446. http://dx.doi.org/10.1086/590649.

Blanchard, Olivier. 2009. "The State of Macro." Annual Review of Economics 1:209-228. http://dx.doi.org/10.1146/annurev. economics.050708.142952.

Blinder, Alan S. 1997. "Is There a Core of Practical Macroeconomics That We Should All Believe?" American Economic Review 87:240-243.

Blyth, Mark. 2002. Great Transformations: Economic ideas and institutional change in the twentieth century. New York: Cambridge University Press. http://dx.doi .org/ 10.1017/CB09781139087230.

Campbell, John L. 1998. "Institutional Analysis and the Role of Ideas in Political Economy." Theory and Society 27:377-409. http://dx.doi .org/10.1023/A: 1006871114987.

Chwieroth, Jeffrey M. 2007. "Testing and Measuring the Role of Ideas: the Case of Neoliberalism in the International Monetary Fund." International Studies Quarterly 51:5-30. http://dx.doi.org/10.1111/j.1468-2478.2007.00437.x.

Converse, Phillip. 1964. "The Nature of Belief Systems in Mass Publics." In Ideology and Discontent, edited by David E. Apter. New York: Free Press.

Crane, Diana. 1972. Invisible Colleges: Diffusion of Knowledge in Scientific Communities. University of Chicago Press.

Dequech, David. 2007. "Neoclassical, mainstream, orthodox and heterodox economics." Journal of Post-Keynesian Economics 30:279-302. http://dx . doi . org/10 . 2753/PKE0160-3477300207.

DiMaggio, Paul, John Evans, and Bethany Bryson. 1996. "Have American's Social Attitudes Become More Polarized?" American Journal of Sociology 102:690. http: //dx.doi.org/10.1086/230995.

Flache, Andreas, and Michael Macy. 2011. "Small Worlds and Cultural Polarization." Journal of Mathematical Sociology 35:146-176. http://dx . doi .org/10 . 1080/ $0022250 X .2010 .532261$. 
Fourcade, Marion. 2009. Economists and Societies: Discipline and Profession in the United States, Britain and France, 1890s to 1990s. Princeton: Princeton University Press. http://dx.doi.org/10.1515/9781400833139.

Fourcade, Marion, Etienne Ollion, and Yann Algan. 2015. "The Superiority of Economists." Journal of Economic Perspectives 29:89-114. http://dx . doi . org/10 . $1257 /$ jep.29.1.89.

Fuller, Dan, and Doris Geide-Stevenson. 2003. "Consensus Among Economists Revisited." Journal of Economic Education 34:369-387. http://dx. doi.org/10. 1080/00220480309595230.

Gordon, Roger, and Gordon B. Dahl. 2013. “Views among economists: Professional consensus or point-counterpoint?" American Economic Review: Papers and Proceedings 103:629-635. http://dx.doi.org/10.1257/aer.103.3.629.

Goyal, Sanjeev, Marco J. Van Der Leij, and José Luis Moraga-González. 2006. "Economics: An Emerging Small World." Journal of Political Economy 114:403-412. http://dx.doi.org/10.1086/500990.

Hall, Robert E. 1976. "Notes on the current state of empirical macroeconomics." Unpublished working paper, Stanford University. http://tinyurl.com/zxjw9vu.

Hirschman, Daniel, and Elizabeth Popp Berman. 2014. "Do economists make policies? On the political effects of economics." Socio-Economic Review 12:779-811. http://dx.doi.org/10.1093/ser/mwu017.

Jelveh, Zubin, Bruce Kogut, and Suresh Naidu. 2014. "Detecting Latent Ideology in Expert Text: Evidence from Academic Papers in Economics." In Proceedings of the 2014 Conference on Empirical Methods in Natural Language Processing, pp. 1804-1809. http://dx.doi.org/10.3115/v1/D14-1191.

Klein, Daniel B., and Charlotta Stern. 2007. "Is There a Free Market Economist in the House? The Policy Views of American Economic Association Members." American Journal of Economics and Sociology 66:309-334. http://dx . doi .org/10. $1111 / \mathrm{j} .1536-7150.2007 .00513 . \mathrm{x}$.

Kogut, Bruce, and J. Muir Macpherson. 2007. "The decision to privatize: economists and the construction of ideas and policies." In The Global Diffusion of Markets and Democracy, edited by Beth A Simmons, Frank Dobbin, and Geoffrey Garrett, pp. 104-140. Cambridge: Cambridge University Press.

Krugman, Paul. 2009. "How Did Economists Get It So Wrong?" The New York Times Magazine, September 6. http://www.nytimes.com/2009/09/06/ magazine/06Economic-t.html.

Krugman, Paul. 2013. "Ideology and Economics." The New York Times, January 5. http://krugman.blogs.nytimes.com/2013/01/05/ ideology-and-economics/.

Lamont, Michèle. 2009. How Professors Think. Harvard University Press. http: //dx.doi.org/10.4159/9780674054158. 
Lazear, Edward P. 2000. "Economic Imperialism." The Quarterly Journal of Economics 115:99-146. http://dx.doi.org/10.1162/003355300554683.

Martin, John Levi. 2002. "Power, Authority and the Constraint of Belief Systems." American Journal of Sociology 107:861-904. http://dx. doi .org/10.1086/343192.

Martin, John Levi, and Matthew Desmond. 2010. "Political position and social knowledge." Sociological Forum 25:1-26. http://dx.doi.org/10.1111/j. 1573-7861.2009.01154.x.

May, Ann Mari, Mary G. Mcgarvey, and Robert Whaples. 2014. "Are disagreements among male and female economists marginal at best?: A survey of AEA members and their views on economics and economic policy." Contemporary Economic Policy 32:111-132. http://dx.doi. org/10.1111/coep.12004.

Mizruchi, Mark S. 1993. "Cohesion, equivalence, and similarity of behavior: a theoretical and empirical assessment." Social Networks 15:275-307. http://dx. doi .org/10.1016/0378-8733(93)90009-A.

Mohr, John W. 1998. "Measuring Meaning Structures." Annual Review of Sociology 24:345-370. http://dx.doi.org/10.1146/annurev.soc.24.1.345.

Moody, James. 2004. “The Structure of a Social Science Collaboration Network: Disciplinary Cohesion from 1963 to 1999." American Sociological Review 69:213-238. http://dx.doi.org/10.1177/000312240406900204.

Önder, Ali Sina, and Marko Terviö. 2015. "Is economics a house divided? Analysis of citation networks." Economic Inquiry 53:1491-1505. http://dx.doi.org/10. 1111/ecin. 12164.

Reay, Mike. 2012. "The Flexible Unity of Economics." American Journal of Sociology 118:45-87. http://dx.doi.org/10.1086/666472.

Rich, Andrew. 2005. Think Tanks, Public Policy, and the Politics of Expertise. Cambridge University Press.

Sapienza, Paola, and Luigi Zingales. 2013. "Economic experts versus average americans." American Economic Review: Papers and Proceedings 103:636-642. http: //dx.doi.org/10.1257/aer.103.3.636.

Schwed, Uri, and Peter S. Bearman. 2010. "The Temporal Structure of Scientific Consensus Formation." American Sociological Review 75:817-840. http://dx.doi . org/10.1177/0003122410388488.

Smith, Noah. 2013. "Is economics divided into warring ideological camps?" Noahpinion blog. http://tinyurl.com/h6cx $2 \mathrm{jj}$.

Stevenson, Betsey, and Justin Wolfers. 2012. "The U.S. Economic Policy Debate is a Sham." BloombergView. http://tinyurl.com/z9ka4rj.

Terviö, Marko. 2011. "Divisions within Academia: Evidence from Faculty Hiring and Placement." Review of Economics and Statistics 93:1053-1062. http://dx.doi . org/10.1162/REST_a_00108. 
Van Gunten, Tod S. 2015. "Cycles of polarization and settlement: diffusion and transformation in the macroeconomic policy field." Theory and Society 44:321-354. http://dx.doi.org/10.1007/s11186-015-9253-8.

Wasserman, Stanley, and Katherine Faust. 1994. Social Network Analysis: Methods and Applications, volume f. Cambridge University Press. http://dx . doi .org/10 . 1017/CB09780511815478.

Wolfers, Justin. 2013. "Comments on Roger Gordon and Gordon Dahl's 'Views among Economists: Professional Consensus or Point-Counterpoint'." Unpublished comments delivered at the American Economic Association annual meeting, January 5, San Diego. http://tinyurl .com/gs9eyep.

Acknowledgements: The authors would like to thank Anil Kashyap, Brian Barry, and the Initiative on Global Markets at the Booth School of Business of the University of Chicago for providing data access.

Tod S. Van Gunten: Max Planck Institute for the Study of Societies.

E-mail: tvg@mpifg.de.

John Levi Martin: Department of Sociology, University of Chicago.

E-mail: jlmartin@uchicago.edu.

Misha Teplitskiy: Institute for Quantitative Social Science, Harvard University.

E-mail: mteplitskiy@fas.harvard.edu. 